\title{
Stratospheric Balloon Flight of Cost-Effective Sampling Bags and High Resolution AirCore to Measure Arctic Greenhouse Gas Concentrations of $\mathrm{CO} 2$ and $\mathrm{CH} 4$
}

\author{
Georges L. J. Labrèche, Pau Molas-Roca, Natalie \\ Lawton, Núria Agües Paszkowsky, Kyriaki Blazaki, \\ Emily Chen, Jordi Coll Ortega, Gustav Dyrssen, Erik \\ Fagerström, Emil Nordqvist, Muhammad Ansyar Rafi \\ Putra, Hamad Siddiqi, Ivan Zankov \\ Division of Space Technology \\ Luleå University of Technology \\ Kiruna, Sweden \\ tubularbexus@googlegroups.com
}

\author{
Rigel Kivi, Pauli Heikkinen \\ Arctic Space Center \\ Finnish Meteorological Institute \\ Sodankylä, Finland
}

\begin{abstract}
There is little information on the distribution of trace gases in the stratosphere due to the inherent difficulty and high cost of air sampling above aircraft altitudes. This paper presents project TUBULAR, implemented under the REXUS/BEXUS programme. TUBULAR is a student-led stratospheric balloon experiment for low-cost air sampling that reduces the current complexities and limitations of obtaining data on stratospheric trace gas distributions. This technology demonstrator was launched from Esrange, in the Swedish Lapland. The balloon payload included two atmospheric samplers: an AirCore sampler and a bag sampling system. The AirCore sampler was a $200 \mathrm{~m}$ long stainless steel tube, which allowed continuous profile sampling during balloon descent. The bag sampling system consisted of six bags, each programmed to be filled at a pre-selected altitude in the stratosphere using a pumping system. This paper presents details on the payload construction and first results obtained by the AirCore sampler.
\end{abstract}

Keywords-Balloon Experiments for University Students; Climate Change; Stratospheric Air Sampling; AirCore; Sampling Bags; Greenhouse Gas; Carbon Dioxide (CO2); Methane (CH4); Carbon Monoxide (CO).

\section{BACKGROUND}

Trace gases make up less than 1\% of the Earth's atmosphere. They include all gases except nitrogen, oxygen, and argon. In terms of climate change, the scientific community is concerned with concentrations of $\mathrm{CO}_{2}$ and $\mathrm{CH}_{4}$ which make up less than $0.1 \%$ of all trace gases and are referred to as greenhouse gases. They are the main offenders of the greenhouse effect caused by human activity as they trap heat in the atmosphere. Larger emissions of greenhouse gases lead to higher concentrations of those gases in the atmosphere thus contributing to climate change.

Researchers have noted that "the Arctic region has warmed more than twice as fast as the global average - a phenomenon known as Arctic amplification" [1]. An ice-free Arctic Ocean is projected as a realistic scenario in future summers, similar to the Pliocene Epoch when "global temperature was only $2-3^{\circ} \mathrm{C}$ warmer than today" [2]. Suggestions that additional loss of Arctic sea ice can be avoided by reducing air pollution and $\mathrm{CO}_{2}$ growth still require confirmation through better climate effect measurements of $\mathrm{CO}_{2}$ and non- $\mathrm{CO}_{2}$ forcings [2]. Such measurements bear high costs, particularly in air sampling for greenhouse gas concentrations in the region between the upper troposphere and the lower stratosphere which have a significant effect on the Earth's climate.

\section{PROOF-OF-CONCEPT}

\section{A. AirCore Limitations}

TUBULAR sought to address the limitations of using an AirCore: a stratospheric balloon sampling system using a long and thin stainless steel tube, shaped in the form of a coil, that takes advantage of changes in pressure during descent to passively sample the surrounding atmosphere and preserve a continuous profile. Details of the AirCore mechanism and resulting profiles have been elaborated in detail with past campaigns such as in [3] and [4].

AirCore sampling during a balloon's descent phase results in a profile shape extending the knowledge of greenhouse gas distributions for the measured column between the upper troposphere and the lower stratosphere [3]. Due to the complexities and mass penalties of including a gas analyzer as part of the payload, analyses of the sampled greenhouse gases are done post-flight after recovery of the experiment.

Despite its proven robustness and notable cost-effectiveness, it is difficult to determine the sampling altitudes of an AirCore [5]. Furthermore, an AirCore constrains the choice of coverage area due to the geographical restrictions imposed by the 
irreversible process of gas mixing along the air column sampled in its stainless tube. As such, the sampling region of an AirCore campaign must remain within proximity to research facilities. It is this constraint that motivated the design of TUBULAR to enable sampling in remote locations where fast recovery of the experiment is unlikely, such as in Arctic regions.

\section{B. Alternative to AirCore}

The proposed alternative sampling system consists of a series of small independent air sampling bags activated in series during flight. Each sampling bag is allocated a vertical sampling range capped at 500 meters, lessening the concerns associated with mixing of gases and enabling a direct determination of sampling altitude. Furthermore, the use of sampling bags eliminates the production costs of a long coil which is the crux of the AirCore system. Sampling bags introduce their own limitations as the discrete approach to sampling in series does not offer the continuous profile made possible by an AirCore. It is possible to mitigate this decreased vertical resolution by scaling the experiment to include more sampling bags. The choice between using an AirCore or sampling bags thus becomes a trade between sampling resolution, production cost, and remoteness of the target sampling location.

The primary objective of TUBULAR consisted of validating the proposed air sampling bag system. This sampling mechanism is henceforth referred to as the Alternative to AirCore (AAC). Samples collected by the AAC were to be validated by comparing concentrations of greenhouse gases against those found in reference samples collected during the same flight by a high resolution $200 \mathrm{~m}$ tube long AirCore, henceforth referred to as the Conventional AirCore (CAC). The secondary objective was to analyze carbon dioxide $\left(\mathrm{CO}_{2}\right)$ and methane $\left(\mathrm{CH}_{4}\right)$ concentrations measured from samples collected by both systems and to contribute the findings to climate change research in the Arctic region. In order to achieve these objectives, both systems were included in a thermally regulated encasing flown as one of the payloads on board a stratospheric balloon provided by the REXUS/BEXUS programme. The sequences of sampling operations were triggered autonomously based on air pressure measurements translated to altitude. Overriding this autonomous sequence was possible via telecommand. A high level design of the payload is presented in Fig. 1.

\section{SAMPLING STRATEGY}

A balloon flight goes through three phases: ascent, float, and descent. The AAC contained six sampling bags, two of which were to collect samples during the ascent phase at $18 \mathrm{~km}$ and 21 $\mathrm{km}$ and the remaining four during the descent phase at $17.5 \mathrm{~km}$, $16 \mathrm{~km}, 14 \mathrm{~km}$, and $12 \mathrm{~km}$. These altitudes were determined by taking into account the time needed to fill the bags with respect to the ambient air pressure at those altitudes and the projected ascent and descent velocities all while satisfying the target 500 $\mathrm{m}$ vertical resolution. The sampling timeline is presented in Fig. 2.

Analysis of the sampled gases was done post-flight, after experiment retrieval, with a Picarro G2401 analyzer located at ground station. A minimum air sample amount of $0.18 \mathrm{~L}$ (at sea level pressure) was required for the analyzer to detect concentrations of $\mathrm{CO}_{2}$ and $\mathrm{CH}_{4}$. Taking into account pressure changes, the minimum volume of air that was needed to be sampled during the ascent phase were $1.8 \mathrm{~L}$ and $2.4 \mathrm{~L}$ for $18 \mathrm{~km}$ and $21 \mathrm{~km}$ respectively. During the descent phase, the minimums were $1.7 \mathrm{~L}, 1.3 \mathrm{~L}, 1.0 \mathrm{~L}$, and $0.7 \mathrm{~L}$ for $17.5 \mathrm{~km}, 16$ $\mathrm{km}, 14 \mathrm{~km}$, and $12 \mathrm{~km}$ respectively. However, the $3 \mathrm{~L}$ size of the sampling bag allowed the experiment to target a sea level pressure air sampling amount of $0.6 \mathrm{~L}$ rather than the worst case $0.18 \mathrm{~L}$.

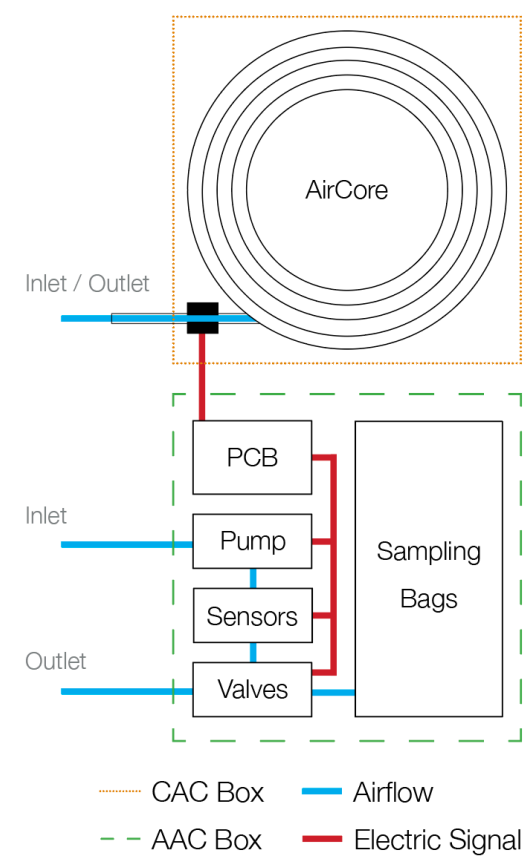

Fig. 1. High level design of the TUBULAR payload.

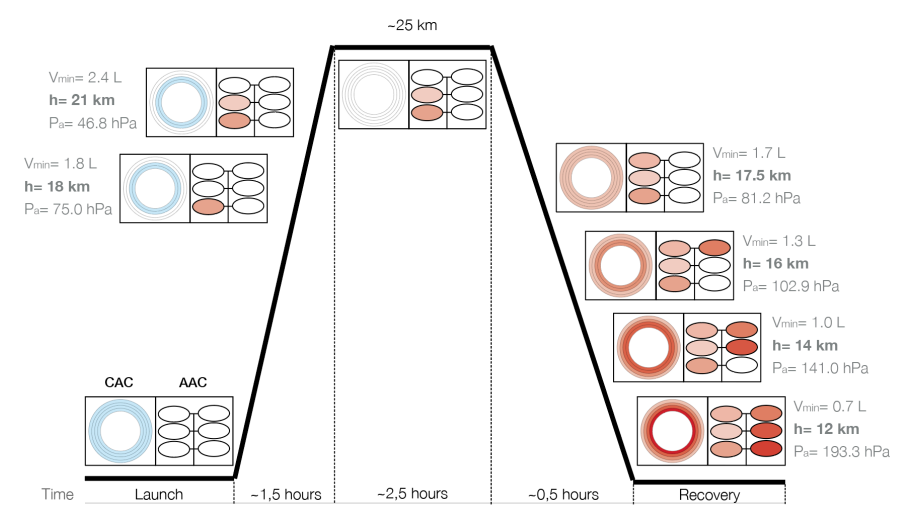

Fig. 2. Air sampling timeline throughout the flight profile for both the CAC and AAC. Vmin, $h$, and $P a$ values are associated with the bag sampling strategy. $V \min$ denotes the minimum quantity of required air sample assigned to the allotted sampling range; $h$ denotes the target altitudes from which sampling begins; $\mathrm{Pa}$ denotes the target air pressure values from which sampling begins. 


\section{A. Ascent Phase}

From a scientific point of view, the primary region of interest for sampling were at the peak altitudes while the balloon was in the stratosphere. Sampling at these altitudes could not occur during the descent phase due to the gondola tumbling and falling at an average speed of $50 \mathrm{~m} / \mathrm{s}$ for approximately two minutes after the balloon cut-off [6]. This descent speed was too large for a sampling bag to be filled within the target vertical resolution of $500 \mathrm{~m}$. Peak altitude sampling with the AAC could thus only be accomplished toward the end of the ascent phase, peaking at approximately $27.3 \mathrm{~km}$.

\section{B. Descent Phase}

The AAC sampling could only initiate once the gondola descent speed had stabilized at $8 \mathrm{~m} / \mathrm{s}$ from approximately $19 \mathrm{~km}$ in altitude [6]. Passive sampling with the CAC was triggered at the beginning of the descent phase based on air pressure measurements. The CAC descent phase sampling was to be used to validate the AAC sampling mechanism by comparing measurements from both samples and using those of the CAC as a reference.

\section{SETUP AND COMPONENTS}

The experiment consisted of two boxes side by side, as shown in Fig. 3. This design allowed easy independent access to and manipulation of either sampling system.

The AAC box houses six sampling bags as well as the pneumatic system and electronics. These components were not distributed across both boxes for the sake of simplicity of design, compactness, and mass reduction. Furthermore, a design favoring future re-flights of the AAC systems was chosen over that of the CAC. Both boxes are mechanically and electrically connected as the CAC relies on the onboard computer housed in the AAC for sensor reading, thermal regulation, valve control, and data logging. The AAC pneumatic system consists of a pump, sensors, tubing, and valves.

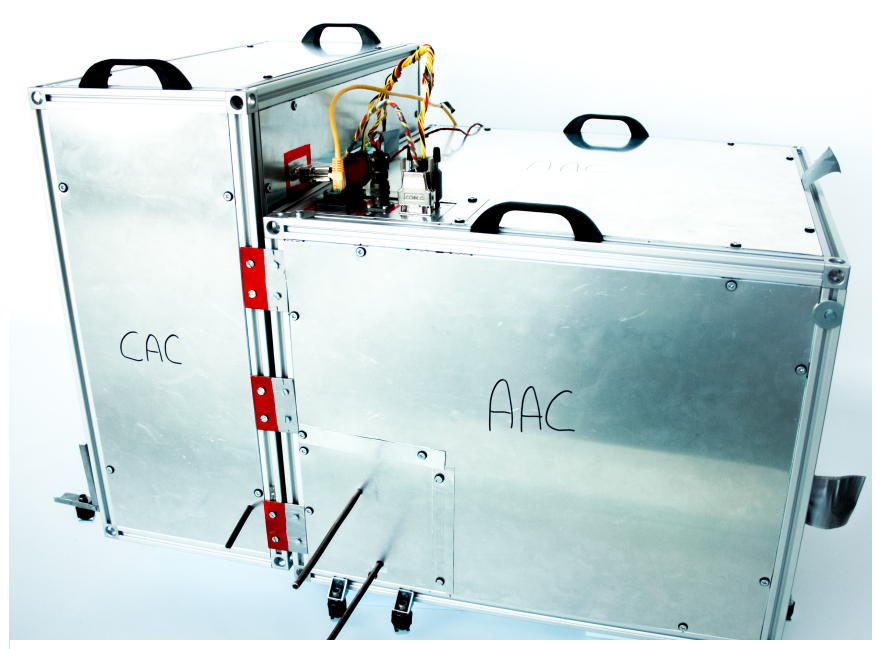

Fig. 3. The flight ready CAC (left) and AAC (right) sampling systems enclosed in their respective boxes. The CAC box containing the AirCore is 0.23 $\mathrm{x} 0.5 \times 0.5 \mathrm{~m}$ and $11.95 \mathrm{~kg}$ while the AAC box containing the sampling bags is $0.5 \times 0.5 \times 0.4 \mathrm{~m}$ and $12.21 \mathrm{~kg}$. The total mass of the experiment is $24.16 \mathrm{~kg}$.
The mechanical components that were selected to build the AAC sampling system were based on requirements relating to inertness and operational robustness in an extreme atmospheric environment. Extensive ground testing was thus performed to validate component reliability at different air pressure levels up to the projected maximum altitude. For instance, the pump was vacuum chamber tested under an air pressure of approximately $23 \mathrm{hPa}$ while simulating performances at $24 \mathrm{~km}$ in altitude. Key components selected for the final design were Restek multi-layer foil gas sampling bags (3 L, 10"x10"), KNF air pump, FMI (Finish Meteorological Institute) magnesium filter tube, SilcoTek tubing - SilcoNert ${ }^{\circledR} 2000$ coated 304SS welded/drawn, SMC Pneumatics valves and manifolds, and Swagelok tubing interfaces, connectors, fittings, and unions. Additionally, key electrical components were Sensor Solutions pressure sensors and a Honeywell airflow sensor.

\section{A. Air Pump}

Due to low ambient pressure at stratospheric heights, the AAC needed to be equipped with an air pump to fill its bags with air samples. The air pump had to ensure an intake rate of at least $3 \mathrm{~L} / \mathrm{min}$ in order to obtain a $500 \mathrm{~m}$ vertical resolution at an ascent speed of $5 \mathrm{~m} / \mathrm{s}$ and a descent speed of $8 \mathrm{~m} / \mathrm{s}$.

\section{B. Tubes and Valves}

The sampled air traveled from the pumps into the sampling bags via the pneumatic system. Each sampling bag was allocated a sampling altitude range and connected to a dedicated valve via a tube. The maximum operating pressure for the tubes are 150 $\mathrm{hPa}$. The valve's leakage rate is $0.001 \mathrm{~L} / \mathrm{min}$. A flushing valve was used to flush the system before each bag would be filled, ensuring that samples came from the desired altitude rather than from leftover air introduced in the tubes from previous sampling.

\section{Sampling Bags}

The AAC system was designed for ease of use, its internal configuration is shown in Fig. 4. The sampling bags were easily accessible from the sides, allowing minimal handling requirements for manual operations such as pre-launch flushing. Filling the sampling bags during the ascent phase introduced a bursting risk due to the air samples expanding inside the bag during the ascent that followed sampling. Ascent phase sampling thus targeted partial bag filling to a maximum bag pressure of $110 \mathrm{hPa}$. However, air compression during the descent was a concern with respect to insufficient air sampling in which case the bags had to be fully filled. Descent sampling targeted a maximum bag pressure of $130 \mathrm{hPa}$ in order to ensure that enough samples were collected for analysis. The maximum bag pressure recommended by the manufacturer is $140 \mathrm{hPa}$.

\section{Pressure Sensors}

Sampling was triggered by the ambient air pressure readings from sensors located outside the experiment box. When air pressure readings indicated pressures expected at a target sampling altitude, the appropriate sampling valve would be activated autonomously and allow air to flow into the sampling bag assigned to the given altitude. Closing the sampling valve was triggered when one of the following two conditions was met: the maximum pressure difference between the inside and 


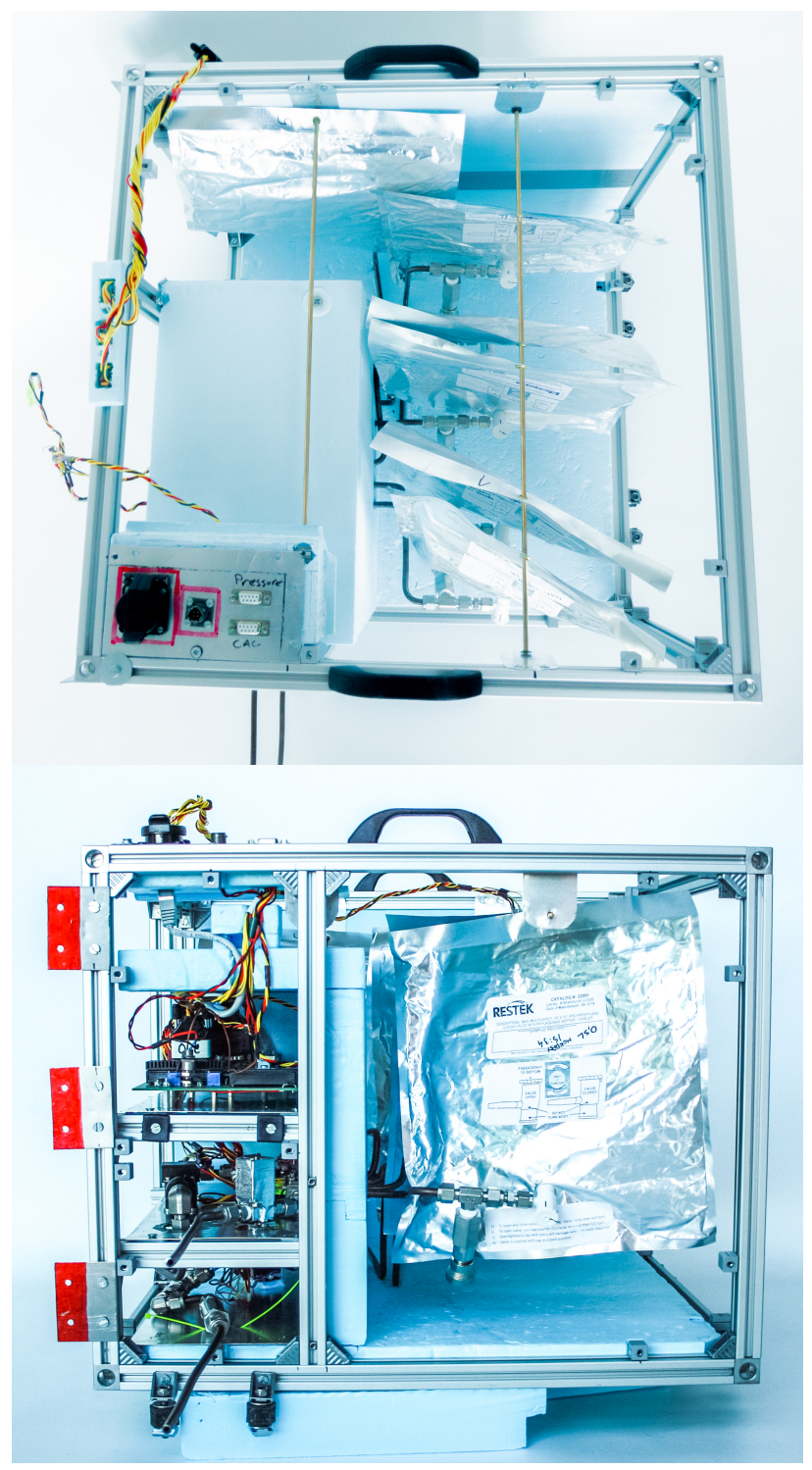

Fig. 4. Restek multi-layer foil gas sampling bags (3 L, 10"x10") in the AAC box, top and front views.

the outside of the bag was reached or a maximum sampling duration had passed. An in-line pressure sensor was used for the former and predetermined sampling durations were calculated for the latter based on vacuum test results and monitored by means of an airflow sensor.

\section{RESULTS}

\section{A. Flight Performance}

The flight began nominally with housekeeping data being downlinked as expected. Thermal systems were observed from the ground station to be operating nominally. After takeoff, the onboard software successfully entered ascent mode and thermal management continued nominally for the rest of the flight. The first AAC sampling altitude of $18 \mathrm{~km}$ was successfully detected by the software; however, the pump failed to switch on and a full reset of the board followed. After the reset had completed, the software successfully switched back to ascent mode at which point manual mode was set via telecommand in order to attempt to remedy the pump. Unfortunately, all attempts proved unsuccessful during both ascent and descent phases.

\section{B. Failure Analysis}

Post-flight investigation revealed that all subsystems operated nominally within expected conditions, including the pump. The observed failures were reproduced after introducing a current limitation by setting the bench power supply from 24 $\mathrm{V}$ and $1.8 \mathrm{~A}$ to $24 \mathrm{~V}$ and $1 \mathrm{~A}$. Based on this finding, a lab analysis was conducted which focused on the pump's power consumption. It was confirmed that the experiment was currentlimited but the source of this limitation was not discovered.

Concerns on introducing contaminants into the system after it was cleaned imposed access restrictions to the gondola which made it impossible to test start the pump during the pre-fight readiness review. As such, this issue should have been detected with a test plan to start the pump while running on batteries at a lab setting.

\section{AirCore Profiles}

The primary objective of validating the AAC as an alternative sampling mechanism was not achieved. However, the AirCore onboard the CAC system operated nominally resulting in high resolution profiles for $\mathrm{CO}, \mathrm{CO}_{2}$, and $\mathrm{CH}_{4}$. These profiles are presented in Fig. 5 and the raw data is available as open data from [7].

Trace gas concentrations are measured in parts per million (ppm) and parts per billion (ppb). A decreasing concentration trend is observed for $\mathrm{CO}_{2}, \mathrm{CH}_{4}$, and $\mathrm{CO}$ as the altitude increases. The maximum values are approximately $407 \mathrm{ppm}$ for $\mathrm{CO}_{2}, 1.9$ ppm for $\mathrm{CH}_{4}$, and close to $89 \mathrm{ppb}$ for $\mathrm{CO}$.

A sharp decrease of $\mathrm{CO}_{2}$ can be observed in the first layers above the tropopause. Tropopause altitude was at $274 \mathrm{hPa}$, about $9.8 \mathrm{~km}$. In the stratosphere, values are lower since the exchange between the upper troposphere and lower stratosphere takes several years [4]. Variability is higher near the ground, which agrees with the idea that $\mathrm{CO}_{2}$ may have negative and positive anomalies at the surface that are mainly associated with vegetation uptake and anthropogenic emissions [4].

The mixing ratios of $\mathrm{CH}_{4}$ have a small variability in the troposphere. A strong decrease in the stratosphere is easy to spot with a value of $1.85 \mathrm{ppm}$ near the tropopause and $1.33 \mathrm{ppm}$ at $15.2 \mathrm{~km}(118 \mathrm{hPa})$. Variability is higher in the mid-to-upper troposphere and in the stratosphere, which is mostly due to positive anomalies coming from the surface and negative anomalies coming from the stratosphere [4].

It is difficult to draw any conclusions based on measurements extracted from a single sampling flight. Variations of greenhouse gas concentrations would have to be observed through time with data collected over numerous reflights. 

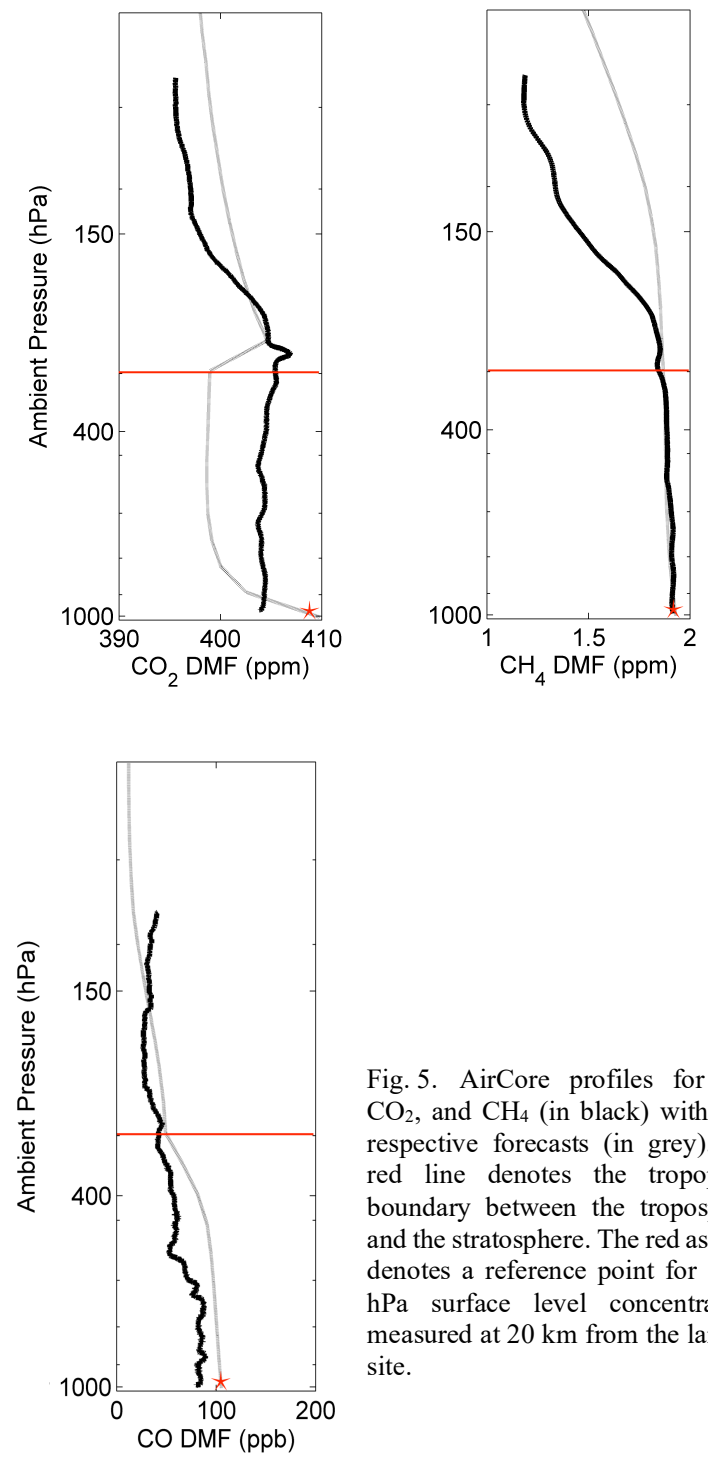

Fig. 5. AirCore profiles for $\mathrm{CO}$, $\mathrm{CO}_{2}$, and $\mathrm{CH}_{4}$ (in black) with their respective forecasts (in grey). The red line denotes the tropopause boundary between the troposphere and the stratosphere. The red asterisk denotes a reference point for 1,000 $\mathrm{hPa}$ surface level concentrations measured at $20 \mathrm{~km}$ from the landing site.

\section{Future Work}

The AAC and CAC systems were segregated from each other in a two-box design so to enable individual re-flights in future campaigns. Since the BEXUS flight, the AAC has been fitted with its own power supply in order to be independent from the REXUS/BEXUS gondola from where it drew its power. The thermal housekeeping data collected during the flight indicates that the temperature inside the box will remain within operational range of the power supply during the entirety of a similar flight profile. A dedicated power supply also enables easier detection of power related issues such as current limitations. The TUBULAR experiment is ready for a re-flight in order to validate the AAC sampling mechanism. The complete Student Experiment Documentation (SED) is available from [7] and is of interest for any future replication efforts.

Finally, it is worth noting that the hold times of the sampling bags are typically 48 hours [8]. Future iterations of TUBULAR could address this limitation by using "a maneuverable glider or return vehicle for easy recovery in the field" as suggested in [3]. Originally proposed for an AirCore, this idea becomes more feasible considering a lessened mass penalty associated with lightweight sampling bags.

\section{ACKNOWLEDGMENT}

The TUBULAR Team wishes to acknowledge the invaluable support received by the REXUS/BEXUS organizers: Swedish National Space Agency (SNSA), German Aerospace Center (DLR), European Space Agency (ESA), Swedish Space Corporation (SSC), Center of Applied Space Technology and Microgravity (ZARM), Esrange Space Centre, and ESA Education. In particular, the team's gratitude extends to the following project advisers who showed special interest in our experiment and its success: Dr. Thomas Kuhn (Luleå University of Technology, LTU), Mr. Olle Persson (LTU), Mr. Grzegorz Izworski (ESA), Mr. Koen Debeule (ESA), Dr. Uwe Raffalski (Swedish Institute of Space Physics, IRF), and Mr. Vincent Still (LTU Alumni). The team would also like to acknowledge sponsorship from manufacturers and suppliers whom showed authentic interest in the experiment as well as providing high performance components and outstanding support: Restek, SMC Pneumatics, SilcoTek, Swagelok Sweden, Teknolab Sorbent, Lagers Masking Consulting, Bosch Rexroth, KNF, and Eurocircuits. From these sponsors, the team is particularly grateful to Dr. Hansjoerg Majer (Restek), David Bengtsson (SMC), Fleming P. Dambo (SMC), Marcus Rydstedt (SMC), René Unglauben (SilcoTek), Fredrik Andersson (Swagelok Sweden), Thomas Norin (Teknolab Sorbent), and Magnus Roman (Teknolab Sorbent).

\section{REFERENCES}

[1] Cohen, Judah \& Screen, James A. \& Furtado, Jason C. \& Barlow, Mathew \& Whittleston, David \& Coumou, Dim \& Francis, Jennifer \& Dethloff, Klaus \& Entekhabi, Dara \& Overland, James \& Jones, Justin. (2014). Recent Arctic amplification and extreme mid-latitude weather. Nature Geoscience. Vol. 7, No. 9. pp. 627-637.

[2] Hansen, James \& Sato, Makiko \& Kharecha, Pushker \& Russell, Gary \& Lea, David W \& Siddall, Mark. (2007). Climate change and trace gases. Philosophical Transactions of the Royal Society A: Mathematical, Physical and Engineering Sciences. 365.

[3] Karion, Anna \& Sweeney, Colm \& Tans, Pieter \& Newberger, Timothy. (2010). AirCore: An Innovative Atmospheric Sampling System. Journal of Atmospheric and Oceanic Technology - J ATMOS OCEAN TECHNOL. 27. 1839-1853. 10.1175/2010JTECHA1448.1.

[4] Membrive, Olivier \& Crevoisier, Cyril \& Sweeney, Colm \& Danis, Francois \& Hertzog, Albert \& Engel, Andreas \& Boenisch, Harald \& Picon, Laurence. (2017). AirCore-HR: a high-resolution column sampling to enhance the vertical description of $\mathrm{CH} 4$ and $\mathrm{CO} 2$. Atmospheric Measurement Techniques. 10. 2163-2181. 10.5194/amt-10-2163-2017.

[5] Hooghiem, Joram J. D., de Vries, Marcel, Been, Henk A., Heikkinen, Pauli, Kivi, Rigel, and Chen, Huilin: LISA: a lightweight stratospheric air sampler. (2018). Atmos. Meas. Tech., 11, 6785-6801.

[6] EuroLaunch. BEXUS User Manual. Version 7.2. 31 Nov 2017.

[7] BEXUS26/TUBULAR, accessed 15 August 2019, https://rexusbexus.github.io/tubular/

[8] Gas Sampling Bags: Cost-Effective Alternatives for Air Sampling, accessed 15 August 2019, https://www.restek.com/pdfs/EVSS1335B$\underline{\text { UNV.pdf }}$ 